\title{
MECANISMOS DE CONTROL DE LOS ACREEDORES EN MATERIA DE “RING-FENCE” (EN EL CONTEXTO DE OPERACIONES DE FINANCIACIÓN DE ADQUISICIÓN)
}

César Herrero Mazarío DLA Piper - Socio

Profesor de Postgrado en Derecho (UPCO-ICADE / Universitat Pompeu Fabra) 


\section{Introducción y delimitación de estudio.}

La financiación empresarial ha ido generando una serie de prácticas y mecanismos contractuales destinados a la tutela de la calidad crediticia (entre ellas, el "ring-fence"), de creciente complejidad y distinto alcance en atención a las características concretas de la operación de que se trate.

La financiación de una adquisición societaria es, sin duda, uno de los escenarios proclives en los que los acreedores, con el objetivo último de proteger el repago de las cantidades prestadas y en defensa de sus legítimos intereses, deberán considerar la posibilidad de acordar con la parte financiada la inclusión en la documentación de una serie de previsiones orientadas a intensificar la supervisión de la situación y desenvolvimiento del negocio de ésta.

$\mathrm{Ni}$ que decir tiene que la mayor o menor rigidez o laxitud de las anteriores previsiones a ser en cada caso objeto de negociación, estará en directa relación tanto con la solvencia del deudor como con la estructura de la adquisición proyectada en cuestión.

Así, en relación con el primer factor, las previsiones contractuales podrían ser más estrictas cuando la acreditada sea una sociedad de propósito específico de nueva creación (en el que el "ring-fence" obedece a la lógica de su condición y la principal fuente de repago descansará, en última instancia, en el balance adquirido) que cuando la compañía adquirente sea una sociedad operativa con un balance sólido y previamente auditado (situación en la que será de vital importancia reevaluar periódicamente su calidad crediticia y comprobar, en definitiva, el no empeoramiento de las probabilidades de impago inicialmente consideradas).

Respecto del segundo de los mencionados factores, es indiscutible que no será para nada lo mismo efectuar la adquisición cuya financiación total o parcial se pretende por una sociedad que ya ostente la condición de acreditada o garante bajo una financiación existente (lo que, como más adelante se detallará, podría llevar a tener que tramitar con carácter previo la obtención de las dispensas que procedan a la luz de la documentación suscrita o incluso a refinanciar aquélla) que implementarla desde una sociedad que no ostente, ni pueda llegar a ostentar, dicha condición (por ejemplo, por ser "hermana" de la sociedad cabecera del grupo y pertenecer por tanto a un perímetro distinto al analizado por los acreedores afectados).

En el presente artículo, analizaremos (dejando al margen cualquier consideración fiscal o relacionada con la prohibición de asistencia financiera) algunas de las posibles previsiones contractuales a ser consideradas en materia de "ring-fence" en el contexto de una nueva operación de financiación de adquisición en el que la condición de acreditada sea ostentada por una sociedad operativa cuya solvencia crediticia sea la primordialmente considerada para el otorgamiento (y mantenimiento en vigor) de la referida financiación.

\section{II. "Ring-fence". Concepto, propósito y posibles razones para su implementación.}

Desde un punto de vista jurídico, el "ring-fen$c e^{\prime \prime}$ podría definirse como un mecanismo contractual consistente en la posibilidad de, por voluntad de las partes implicadas, delimitar el respaldo económico que constituya el perímetro de recurso de la transacción vía compartimentación y separación de activos y pasivos (de tal manera que dentro del seno del nuevo grupo consolidado resultante de la adquisición pretendida se crearán varios compartimentos -sub-grupos- integrados 
por activos y pasivos separados los unos de los otros -" ring-fenced"-).

El fin del referido mecanismo será intentar tanto proteger a las entidades acreditantes al amparo del contrato de financiación en cuestión como preservar durante su vida la calidad crediticia de la parte acreditada (y, en su caso, la de sus actuales filiales que ostenten o puedan llegar a ostentar la condición de garantes), lo que ineludiblemente exigirá valorar la posibilidad de incluir en la documentación respectiva las pertinentes previsiones al efecto ${ }^{1}$.

Las razones para su implementación pueden ser múltiples pero, fundamentalmente, pueden encontrarse en dos escenarios:

(i) cuando la sociedad (y, en su caso, filiales) cuya adquisición se pretende (sub-grupo target) cuente en sus libros con deuda existente garantizada (vía garantía real y/o personal) cuya documentación asimismo impida su integración contractual en la nueva operación de financiación para su adquisición (lo que implicará necesariamente solicitar la inaplicación de diversas obligaciones contractuales habituales en materia de cambio de control, negative pledge, pari passu, nivel y tipología de endeudamiento permitido, etc.); o

(ii) cuando la integración del mencionado sub-grupo target en el perímetro del sub-grupo adquirente (formado por la sociedad financiada y sus actuales filiales), podría generar un eventual empeoramiento del valor de este último con motivo de cualquier posible traslación futura de responsabilidades desde aquél a éste (sin perjuicio de que la parte financiada, dentro del ámbito de discrecionalidad empresarial que le sea propio $^{2}$, pueda considerar como positiva dicha integración y esperar que la misma redunde en beneficio del nuevo grupo consolidado $y$, en definitiva, en una mayor solidez futura del negocio y balance resultantes).

\section{Algunas previsiones contractuales en materia de "Ring-fence".}

Como ya anticipado, no será difícil convenir que, en el contexto que nos ocupa, será de vi-

\footnotetext{
${ }^{1}$ Respecto de materias como, por ejemplo, el reparto de dividendos y otras retribuciones de capital, salidas de caja fuera del perímetro protegido, otorgamiento de garantías, la venta o adquisición de activos, niveles de endeudamiento con y sin recurso o el suministro de información financiera específica incluyendo y/o excluyendo, según corresponda, las magnitudes correspondientes a los distintos sub-grupos.

2 Discrecionalidad legalmente conferida en virtud del apartado 1 del artículo 226 del Real Decreto Legislativo 1/2010, de 2 de julio, por el que se aprueba el texto refundido de la Ley de Sociedades de Capital, cuyo tenor literal establece que «en e/ ámbito de las decisiones estratégicas y de negocio, sujetas a la discrecionalidad empresarial, el estándar de diligencia de un ordenado empresario se entenderá cumplido cuando el administrador haya actuado de buena fe, sin interés personal en el asunto objeto de decisión, con información suficiente y con arreglo a un procedimiento de decisión adecuadon, en el bien entendido de que no obstante la existencia de sinergias (o, incluso, bases imponibles negativas de las que pueda beneficiarse el sub-grupo adquirente) siempre deberán extremarse los deberes de diligencia y contar, de resultar ello posible, con los correspondientes informes de terceros que así lo respalden (lo que contribuirá al buen fin de la transacción y a dotar de una mayor seguridad jurídica a su realización)
} 
tal importancia configurar un mapa contractual ad hoc que contenga los controles, límites y restricciones que resulten más adecuados para intentar asegurar durante la vida de la financiación el mantenimiento o, en su caso, restauración de la calidad crediticia del perímetro aceptado como principal fuente de repago, debiendo por tanto ser objeto de negociación entre la parte acreedora y la parte financiada la posible introducción en la documentación de diversas cláusulas destinadas, en definitiva, a mantener y preservar el valor de tal perímetro.

En atención a todo lo anterior, consideramos necesario analizar la conveniencia de incluir en la documentación en que se formalice la concreta operación de financiación todos o algunos de los siguientes aspectos ${ }^{3}$ (respecto de los que se deberá reconocer formalmente por las partes que son esenciales y determinantes para la prestación por las entidades acreditantes de su consentimiento y la consiguiente concesión por éstas de dicha financiación):

(i) La inserción de una condición específica (previa o simultánea a la firma del contrato de financiación) consistente en la entrega de un certificado a ser emitido por personas con facultades suficientes al efecto (idealmente en nombre de la sociedad cabecera del sub-grupo target), en virtud del cual se confirme que el cambio de control que tendrá lugar con motivo de la perfección de la adquisición prevista no supondrá el vencimiento financiero anticipado de su deuda en vigor.

(ii) Considerar como supuesto de amortización anticipada obligatoria total que, en cualquier momento durante la vigencia de la operación de financiación, el saldo vivo conjunto de las financiaciones, garantías o contragarantías otorgadas o depósitos constituidos por sociedades del sub-grupo adquirente a favor de sociedades del sub-grupo target sea superior a un determinado importe a convenir (lo que debería complementarse con la consecuente declaración periódica específica al respecto).

(iii) Complementar las obligaciones habituales de suministrar regularmente información financiera y estados contables con otras específicas (idealmente certificadas por el auditor) de confirmación del saldo vivo bajo las financiaciones, garantías o contragarantías otorgadas o depósitos constituidos antes referidos.

(iv) Con el fin de facilitar una imagen fiel de la situación de balance post-adquisición, nuestra recomendación sería que, en materia de cómputo y, en su caso, cumplimiento de los ratios financieros que sean previstos en la documentación de la financiación, se solicitase a la sociedad financiada que fuesen facilitados los cálculos de tales ratios, incluyendo y/o excluyendo (a nivel consolidado/agregado, según corresponda) las magnitudes correspondientes al sub-grupo

\footnotetext{
${ }^{3}$ Todo ello, sin perjuicio de cualesquiera otros requisitos o limitaciones cuya inclusión sea considerada oportuna por los comités de riesgos de cada entidad acreedora participante de cara a evitar un debilitamiento o aminoramiento del patrimonio de la parte obligada que se tuvo originalmente en consideración al decidir conceder dicha financiación.
} 
target.

(v) Acordar la obligación de mantener (en el sub-grupo adquirente) una determinada caja mínima anual con el fin de asegurar debidamente el pago del servicio de la deuda.

(vi) Incorporar, en su caso, un compromiso de no realizar (desde el sub-grupo adquirente) aportación dineraria o no dineraria alguna al sub-grupo target (en concepto de capital social, prima de emisión o equivalente) por un importe superior al que sea inicialmente acordado entre las partes para toda la vida de la financiación.

(vii) Restringir el otorgamiento de financiación desde el sub-grupo adquirente al sub-grupo target (estableciendo para ello un doble umbral de control -tanto vía saldo vivo máximo específico como el que permita también el cumplimiento del nivel admisible de Deuda Financiera Neta que Ilegue a consensuarse- ${ }^{4}$ ).

(viii) Incluir una limitación a que cualquier endeudamiento futuro en que puedan incurrir cualquiera de las sociedades pertenecientes al sub-grupo target se formalice sin posibilidad de recurso alguno a cualquier sociedad integrante del sub-grupo adqui- rente.

(ix) Exigir que las acciones/participaciones de la sociedad cabecera del sub-grupo target no sean objeto de pignoración a favor de terceros (excepcionalmente para el caso de que las partes de la operación no acuerden su pignoración -como es lo habitual en este tipo de financiaciones estructuradas-).

(x) Impedir la realización de operaciones de reestructuración societaria entre compañías pertenecientes a los distintos sub-grupos ${ }^{5}$ (con el propósito de impedir una comunicación de responsabilidades que desvirtúe el propósito del pretendido "ring-fence") salvo que se obtenga el preceptivo consentimiento previo de la parte acreedora.

(xi) Articular un compromiso contractual de no solicitar, en la medida en que ello resulte conveniente y/o posible, la aplicación del régimen de consolidación fiscal a efectos del Impuesto sobre Sociedades ni la aplicación del régimen de grupo a efectos del Impuesto sobre el Valor Añadido ${ }^{6}$.

(xii) Incorporar como causas de resolución anticipada especiales:

- la aparición de pasivos contingentes

\footnotetext{
${ }^{4}$ Umbrales que podrían, en su caso, verse ajustados al alza si el importe destinado a dicha financiación tiene su origen en distribuciones contractualmente permitidas pero no voluntariamente realizadas.

Nótese, adicionalmente, que un efectivo control de lo anterior estará únicamente garantizado si se pacta contractualmente que queden incluidas dentro del cómputo de la referida Deuda Financiera Neta (i) cualesquiera operaciones de financiación concedidas por parte de una sociedad del sub-grupo adquirente a cualquier sociedad del sub-grupo target (computándose dichas financiaciones, a tales efectos, como si las mismas hubieran sido concedidas a sociedades del sub-grupo adquirente), y (ii) cualquier pago que, por razón del régimen de consolidación fiscal que en su caso resulte aplicable, sea realizado por cualquier sociedad del sub-grupo adquirente por cuenta de cualquier sociedad del sub-grupo target.

${ }^{5}$ Esto es, si se acordase su fusión o escisión (salvo entre las sociedades del sub-grupo adquirente o entre las sociedades del sub-grupo target).

${ }^{6}$ Con la inclusión de la cautela anterior, al no estar permitida la solicitud del régimen de consolidación fiscal sin contravenir la documentación en que se instrumentaría la operación de financiación, estaría excluyéndose la posibilidad de que el sub-grupo adquirente estuviera obligado a responder solidariamente del pago de deuda tributaria correspondiente al sub-grupo target.
} 


\section{MECANISMOS DE CONTROL DE LOS ACREEDORES EN MATERIA DE "RING-FENCE" (EN EL CONTEXTO DE OPERA- CIONES DE FINANCIACIÓN DE ADQUISICIÓN) \\ César Herrero Mazarío}

que no figuren en los estados contables o en la información complementaria aportada por la dirección financiera de la parte obligada a las entidades acreditantes:

- la contravención de los compromisos específicos anteriormente mencionados en la presente sección de este estudio; $\mathrm{y}$

- cuando cualquier sociedad perteneciente al sub-grupo target suscriba o mantenga en vigor algún contrato o documento que, por cualquier motivo, conlleve la existencia de recurso a bienes y/o derechos titularidad de cualquier sociedad perteneciente al sub-grupo adquirente en términos distintos a los contractualmente permitidos.

\section{IV. "Ring-fence" y administración de hecho.}

Aunque el catálogo de previsiones contractuales que en cada caso llegue finalmente a ser acordado podría llegar a suponer una limitación a la libertad de actuación de la parte deudora en determinados aspectos relevantes para su actividad económica, interesa sin embargo subrayar que, en nuestra opinión (y en línea con la más reciente doctrina jurisprudencial del Tribunal Supremo ${ }^{7}$ ), su incorporación y observancia no debería en modo alguno suponer para la parte acreedora entrar en la zona de riesgo de la administración de hecho ya que tales previsiones tendrán siempre su origen en el libre consentimiento de las partes (quienes serán soberanas para fijar el contexto jurídico y económico que para la transacción estimen más adecuado), constituirán una contrapartida pactada para la obtención de la financiación solicitada y se orientarán, únicamente, a la legítima tutela del derecho de crédito de los acreedores financieros.

${ }^{7}$ La STS de 8 de abril de 2016 (que reproduce la STS de 22 de julio de 2015, que a su vez se remitía a la precedente STS de 4 de diciembre de 2012), considera que se está ante una situación de administración de hecho "cuando la actuación supone el ejercicio efectivo de funciones propias del órgano de administración de forma continuada y sin sujeción a otras directrices que las que derivan de su configuración como órgano de ejecución de los acuerdos adoptados por la junta general' y, como manifestación de lo anterior, cuando "(i) se haya fijado la política financiera de la concursada»; (ii) "se impartieran instrucciones sobre la contabilidad o sobre la formulación de las cuentas anuales»; (iii) "se haya intervenido en la selección o gestión de clientes [....》. 